\title{
On the Numerical Modeling of Buoyancy-dominated Turbulent Fires by Using Large Eddy Simulation
}

\author{
H. Y. WANG and P. JOULAIN \\ Laboratoire de Combustion et de Détonique \\ C.N.R.S. UPR 9028 -E.N.S.M.A., Université de Poitiers \\ BP 109 - Site du Futuroscope \\ 86960, Futuroscope Cedex, France
}

\begin{abstract}
This study concerns the modeling of three characteristic buoyancy-dominated turbulent diffusion flames such as pool-like, vertical and interaction between pool-like and vertical wall fires. Controlling mechanisms of three dimensional flow, combustion, soot production and radiation are coupled with a Large Eddy Simulation (LES). An EddyBreak-Up concept which accounts for the interaction between combustion and turbulence, is implemented in LES. The numerical models have been validated using experimental data from three turbulent diffusion flames. The predicted mean temperature, velocity and total heat feedback from the high temperature gases in the flame to the wall surface follow closely to the experimental data. Moreover, it is found that LES successfully predicted the important features of highly oscillating buoyancy-controlled pool-like fire (recirculation zone, narrowing and broadening of the flame). While, the standard Smagorinsky sub-grid scale model should be improved to predict the variation of the fluctuating velocity and temperature for the vertical wall fires.
\end{abstract}

KEYWORDS: modeling, CFD, fire investigation, heat transfer

\section{INTRODUCTION}

A large number of studies [1-7] have been performed on the characteristics of buoyant diffusion flames above horizontal or vertical gaseous or liquid fuel burners. Becker [2] et Bouhafid [3] have demonstrated that, in the natural convection limit, as the Froude number decreases, coherent structures appear in the reactive zone, the flame presenting a pronounced instability due to buoyancy. The detailed measurements of the flame and flow structures for three characteristic fire configurations, such as pool-like fire, vertical wall fire and interaction between pool-like and vertical wall fires in medium-scale, have been performed by Annarumma et al. [5]. Several authors [6,7] have shown the limit of the use of Reynolds Averaged Navier-Stokes (RANS) $\mathrm{k}-\varepsilon$ turbulence model to simulate the highly oscillating buoyancy-induced turbulent diffusion flame. The main difficulty lies in the modeling of the entire process including a fluctuating, laminar, diffusion flame at the fire base due to buoyancy, and a turbulent, intermittent one as it evolves upward along the fire plume.

This article presents an application of Large-Eddy-Simulation (LES) for solving the fluid dynamic equations of three-dimensional elliptic, reacting flow. In this work, the fire itself is prescribed in a manner consistent with mixing-controlled combustion. For the first time, combustion and soot models both based on an Eddy-Break-Up (EBU) concept [8] have been implemented in LES. The large scale transport of combustion products can be simulated directly, but combustion processes occuring at small length and time scales are 
represented in an approximate manner through the standard Smagorinsky sub-grid scale model [9]. A radiative transfer equation is solved through the use of a Finite Volume Method [10]. Radiative emission and absorption in the gas-soot mixture is included by using Modak model [11]. The present work uses finite-difference method to discretize the appropriate conservation equations. Three characteristic fire configurations are chosen to validate the numerical models. The mean temperature, velocity, fluctuation and heat flux are compared with the experimental data, and a good agreement is observed.

\section{THEORETICAL ANALYSIS}

The starting point of the analysis is the set of an approximate form of the Navier-Stokes equations appropriate for low Mach number applications. The approximation involves the filtering out of acoustic waves while allowing for large variations in temperature and density [10]. This set consists of the following equations : the continuity equation, the three momentum equations in each of the three space dimensions, the conservation equation for the mass fraction of chemical species, the conservation equation for soot production, and the radiative transfer equation. The key features of each of these will be briefly described.

\section{Flowfield Model}

LES is based on a filtering operation, which decomposes a full flowfield, $\phi(x, t)$, into a resolved component $\bar{\phi}(x, t)$ and a SubGrid-Scale (SGS) component $\phi^{\prime}(x, t)$ [9]. Applying the filtering operation to each term in the conservation equations of mass, momentum, energy and species, and decomposing the dependent variables $(u, v, w, p$, etc) into resolved and subgrid components results in the filtered governing equations, shown below :

$\frac{\partial \rho}{\partial t}+\frac{\partial \rho \bar{u}_{j}}{\partial x_{j}}=0$

$\frac{\partial \rho \bar{u}_{i}}{\partial t}+\frac{\partial\left(\rho \bar{u}_{i} \bar{u}_{j}\right)}{\partial_{X_{j}}}+\frac{\partial \bar{p}}{\partial x_{i}}-\rho g_{i}=\nabla \bar{\tau}_{i j, S G S}$

where an overbar denotes the filtered variable. The unresolved field, $\phi^{\prime}(x, t)$, is modeled by the Smagorinsky model [9]. In this model, the SGS Reynolds stresses tensor, $\bar{\tau}_{i j, S G S}$, are related to the local large scale rate of strain.

$\bar{\tau}_{i j, S G S}=2 \mu_{t} \bar{S}_{i j}, \bar{S}_{i j}=\frac{1}{2}\left(\frac{\partial \bar{u}_{i}}{\partial x_{j}}+\frac{\partial \bar{u}_{j}}{\partial x_{i}}\right)$, and $\mu_{t}=C_{s}^{2} \rho \Delta^{2}\left|\bar{S}_{i j}\right|$

Here, $\left|\bar{S}_{i j}\right|$ is the magnitude of the large scale strain rate tensor $\bar{S}_{i j}$, and $\Delta$ the filter width. In the calculations, the length scale of eddy viscosity is tied to the grid as $\Delta=(\Delta x \Delta y \Delta z)^{1 / 3}$, and its time scale is determined by the local resolvable dissipation 
rate. In this study, the standard value of $\mathrm{C}_{\mathrm{s}}=0.2$ is assigned. The SGS turbulent scalar flux is based on an eddy viscosity assumption, resulting in the following equation :

$$
\frac{\partial \rho \bar{\phi}}{\partial t}+\frac{\partial\left(\rho \bar{u}_{i} \bar{\phi}\right)}{\partial_{x_{j}}}=\frac{\partial}{\partial_{x_{j}}}\left(\frac{\mu_{t}}{\sigma_{\phi}} \frac{\partial \bar{\phi}}{\partial x_{j}}\right)+S_{\phi}
$$

where $\sigma_{\phi}$ denotes the turbulent Prandtl or Schmit number $\left(P r_{t}=S c_{t}=0.5\right)$. For the energy equation, $S_{\phi}$ in Eq. 4 includs the rate of heat release per unit volume, $\dot{q}_{c}$, and the radiant energy flux, $q_{r}$. Finally, the perfect gas law is used to describe the equation of state.

\section{Combustion Model}

It is assumed that chemical reaction of propane in air proceeds through a single irreversible step,

$\mathrm{C}_{3} \mathrm{H}_{8}+5 \mathrm{O}_{2} \rightarrow 3 \mathrm{CO}_{2}+4 \mathrm{H}_{2} \mathrm{O}$

The combustion processes are governed by the conservation equation for the filtered mass fraction of fuel gases $\left(\bar{Y}_{f}\right)$, oxydan $\left(\bar{Y}_{o}\right)$ and products $\left(\bar{Y}_{\mathrm{CO} 2}, \bar{Y}_{\mathrm{H} 2 \mathrm{O}}\right)$, written as

Eq. 4. The gas-phase oxidation reaction is characterized by a mixing rate model for which the local reaction rate, $\dot{\omega}_{f}$, is calculated from an Eddy Break-Up (EBU) concept [8],

$\dot{\omega}_{f}=-\rho C_{E b u} \frac{\varepsilon}{k} \min \left(\bar{Y}_{f}, \frac{\bar{Y}_{o}}{v_{f}}\right)$

Here $v_{f}$ is mass stoichiometric oxidant/fuel ratio, and $\mathrm{C}_{\mathrm{Ebu}}$, is the EBU constant given the value 4 . The turbulent kinetic energy and its dissipation are induced from the eddy viscosity and its length scale,

$k=\left(\frac{\mu_{t}}{C_{\mu} \rho \Delta}\right)^{p}, \quad \varepsilon=C_{\varepsilon} \frac{k^{3 / 2}}{\Delta}$

Here $C_{\mu}$ and $C_{\varepsilon}$ are constants given the value 0.0856 and 0.845 , respectively. Finally, the heat release rate is directly proportional to the rate of consumption of fuel,

$\dot{q}_{c}=-H_{f} \dot{\omega}_{f}$

Here, $H_{f}$ is the heat release rate per unit mass of fuel consumed.

\section{Soot Formation and Oxydation}

The soot formation and its oxidation are incorporated into a turbulent flow calculation in two convection-diffusion equations, expressed as Eq. 4 in which $\bar{\phi}$ represent the 
precursor particles density, $n$, and soot number density, $N$. The expression for the rate of radical nuclei and soot formation, $\dot{\omega}_{\phi, F o r m}$, is given in Ref. [8]. The interaction between soot combustion and turbulence is modeled according to the Eddy-Break-Up concept [8], formulated as,

$\dot{\omega}_{\phi, \text { Oxid }}=C_{E b u} \rho \bar{\phi} \frac{\varepsilon}{k} \min \left(1, \frac{\rho \bar{Y}_{o}}{m_{s} N v_{s}+\rho \bar{Y}_{f} v_{f}}\right)$

Here, $v_{s}$ is the stoichiometric oxygen requirement to burn $1 \mathrm{~kg}$ soot, and $m_{s}$ the mass of a soot particle.

\section{Radiation Model}

The radiation intensity, $I$, is found by solving the radiative transfer equation without scattering,

$$
\vec{\nabla} \cdot \vec{\Omega} I+\kappa I=\kappa \frac{\sigma_{\bar{T}}^{4}}{\pi},
$$

This equation is solved through the use of a Finite Volume Method [10]. The radiative source term, $q_{r}$, in the energy equation is calculated from the divergence of the radiative flux. The overall absorption coefficient, $\kappa$, for the soot and gas mixture is determined through Modak model [11] in function of the temperature and concentration of combustion products. The soot volume fraction $\left(f_{v}\right)$ is obtained at any location from soot number density, N. Here, it is assumed that soot particles are spherical with an uniform diameter $\left(d_{p}=0.02 \mu \mathrm{m}\right)$.

$$
q_{r}=-\int_{4 \pi} \vec{\nabla} \cdot \vec{\Omega} I \cdot d \Omega \approx \kappa\left(\sum_{l=1}^{L} w^{l} I^{l}-4 \sigma \bar{T}^{4}\right), \quad \quad f_{v}=\frac{1}{6} \pi d_{p}^{3} N
$$

\section{Method of Resolution}

The finite-difference technique is used to discretize the partial differential equations. This procedure entails the subdividing of the calculation domain into a finite number of cells. The velocities $\left(u_{i}\right)$ are taken on the boundary of each cell; and all the scalar variables are taken at cell centers. This staggered grid leads to a very efficient differencing scheme for the equations. All spatial derivatives are approximated by second-order central differences and the flow variables are updated in time using an explicit second-order Runge-Kutta scheme. The pressure is found by taking the divergence of the momentum equations, yielding a Poisson equation which is solved with a direct solver developped by McGrattan [10]. The no-slip condition is imposed by setting all velocities to zero at the inert solid surface. 


\section{RESULTS AND DISCUSSION}

The predicted flame structures and the coordinate system adapted in numerical simulation for the three propane diffusion flames are shown in Fig. 1(a,b,c). In general, the pool-like fire is characterized by an initially weak Froude number, and strongly influenced by the gravity force. While, for the vertical wall fires, the dominant aerodynamic parameter is the Grashof number. The first flame (Fig. 1a) is stabilized on a horizontal rectangular porous burner (pyrolysis zone) with a $0.25 \mathrm{~m}$ long (x) by $0.4 \mathrm{~m}$ wide (y) slot with a heat release rate of $36 \mathrm{~kW}$. The 3D computational domain are $1.5 \mathrm{~m}$ $\mathrm{x} 1 \mathrm{~m} \mathrm{x} 2 \mathrm{~m}$ in the $\mathrm{x}, \mathrm{y}$ and $\mathrm{z}$ directions, respectively. The numerical grid is uniform in the $\mathrm{y}$ direction and stretched in the $\mathrm{x}$ and $\mathrm{z}$ directions. A typical $3 \mathrm{D}$ grid contained about 200,000 grid points (60x44x82). About 20h CPU time are needed for $20 \mathrm{~s}$ of simulated real time on a workstation Compaq. The second (Fig. 1b) results from the interaction between a vertical rectangular porous burner (pyrolysis zone) with a height (z) of $1 \mathrm{~m}$ by $0.4 \mathrm{~m}$ wide (y) and the previous pool-like fire at the floor level with a total heat release rate of $108 \mathrm{~kW}$. The 3D computational domain are $1.5 \mathrm{~m} \mathrm{x} 1 \mathrm{~m} \mathrm{x} 3.5 \mathrm{~m}$ in the $\mathrm{x}, \mathrm{y}$ and $\mathrm{z}$ directions, respectively. Cell sizes are $1 \mathrm{~cm}$ near the wall and stretch to about $5 \mathrm{~cm}$ far away from the wall region. A typical 3D grid contained about 240,000 grid points (60x44x104). The last flame (Fig. 1c) is a buoyancy-driven fire propagation behind a vertical rectangular porous burner (pyrolysis zone) of $\mathrm{H}_{\mathrm{b}}=0.5 \mathrm{~m}$ in height (z) by $0.4 \mathrm{~m}$ wide (y) with a heat release rate of $72 \mathrm{~kW}$. The 3D computational domain are $1.8 \mathrm{~m} \mathrm{x} 2$ $\mathrm{m} \times 6 \mathrm{~m}$ in the $\mathrm{x}$, y and $\mathrm{z}$ directions, respectively. About $60 \mathrm{~h}$ CPU time are needed for 60 $\mathrm{s}$ of simulated real time for establishing the heat flux downstream behind the burner.

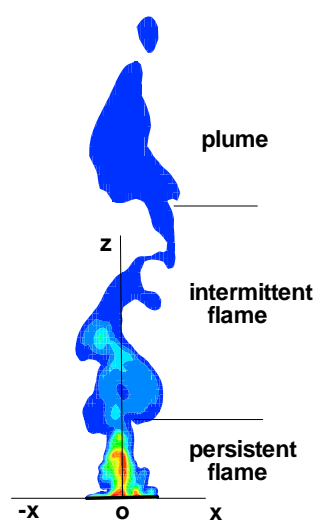

a) pool-like fire

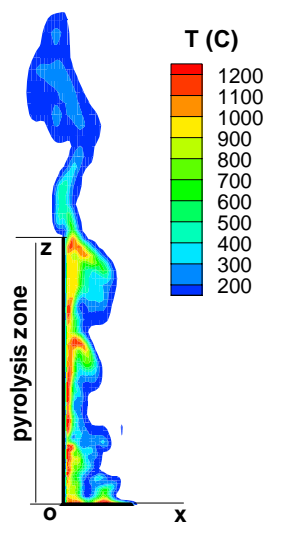

b) pool-like/vertical wall fires

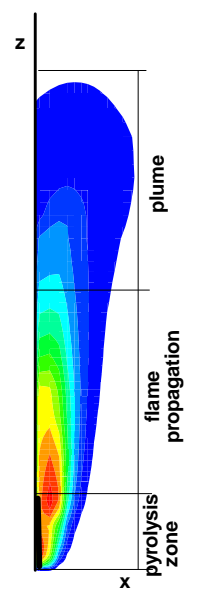

c) wall fire propagation

Fig. 1. Predicted temperature contours for the three propane diffusion flames and the coordinate system $(\mathrm{x}, \mathrm{y}, \mathrm{z})$. Here, $\mathrm{y}$ is perpendicular to the $\mathrm{x}-\mathrm{z}$ plan.

For the three characteristic fires, the combustible gases are injected through the porous plates at extremely low velocities (few $\mathrm{mm} / \mathrm{s}$ ), simulating the pyrolysis rate of a condensed fuel. The free boundaries are located sufficiently far away from the fire to minimize a numerical perturbation. Temperatures were obtained by means of fine wire thermocouples. Velocities were determined using a two-component laser doppler velocimetry (LDV) system. The experimental data for the temperature and velocity fields 
being available only in the symmetrical plane $x-z$, the numerical results are only examined in this plane.

At first, the calculated values of the pool-like fire (cf. Fig. 1a), such as the mean temperature $\mathrm{T}$, the mean longitudinal velocity, $\mathrm{w}$, in the direction $\mathrm{z}$, and transversal one, $\mathrm{u}$, in the direction $\mathrm{x}$, are compared with the experimental data in Fig. 2(a,b,c). The locations of the peak temperature are in good agreement with experiments, while lateral extent of the flame is underestimated. The use of the EBU combustion model based on a one-step irreversible chemical reaction is not sufficient to improve the prediction of the lateral flame extent. The profiles of the longitudinal velocity, w (cf. Fig. 2b) are in close agreement with the experimental values. The entrainment air velocity near the burner surface is also correctly predicted, confirmed by the profile of the transverse velocity, $u$ (cf. Fig. 2c) which is in close agreement with the experimental data at $\mathrm{z}=0.015 \mathrm{~m}$. However, the entrainment air is not well described by the model for the far downstream

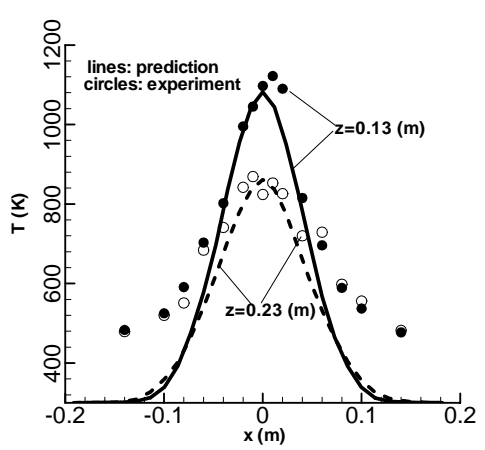

a) temperature

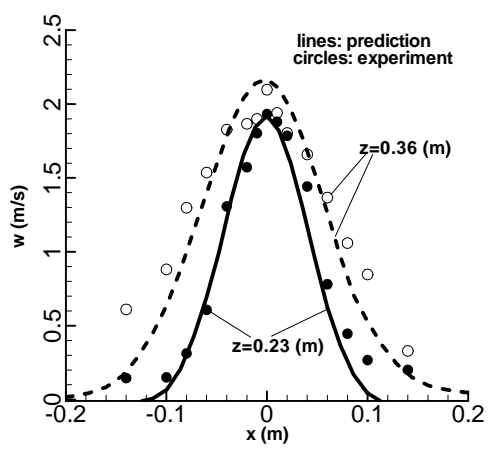

b) longitudinal velocity

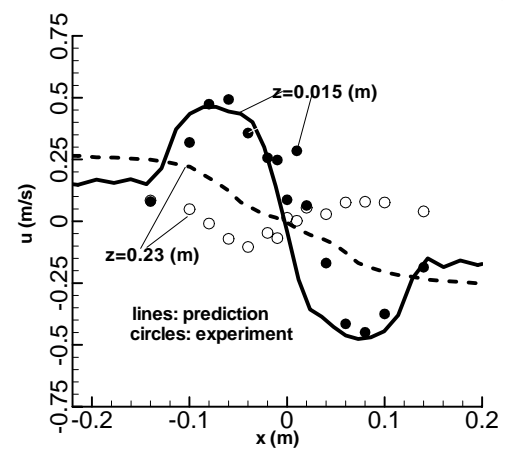

c) transversal velocity

Fig. 2. Comparison between the predicted and measured mean value.

location $(\mathrm{z}=0.23 \mathrm{~m})$. Profiles of the longitudinal velocity fluctuation, $\mathrm{w}^{\prime} \mathrm{w}^{\prime}$, and the transversal one, u'u', at $\mathrm{z}=0.035$ and $0.46 \mathrm{~m}$, are compared with the experimental data in Fig. 3 and Fig. 4. From Fig. 1a, it can be seen that at the flame base, immediately above the burner surface $(\mathrm{z}=0.035 \mathrm{~m})$, is the intermittent zone with a fluctuating, turbulent character which coincides with the periodic formation of large turbulent structures. In general terms, the comparison between prediction and experiment is reasonably good, although the transversal velocity fluctuation, u'u', is clearly underestimated. Globally, the numerical model is capable of reproducing the mechanism generating the buoyant 
instability present in the early development of the flame and the transition to turbulence in the lower part of the fire $(\mathrm{z}=0.035)$.

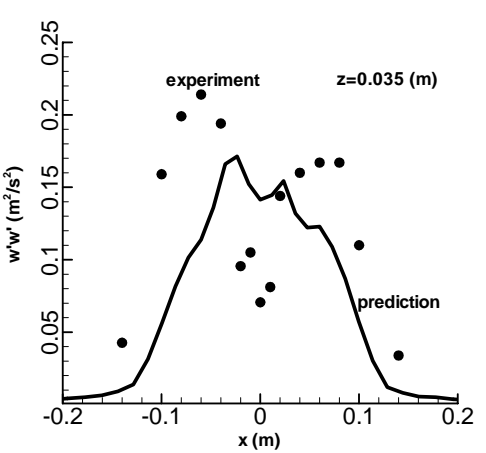

a) $\quad \mathrm{z}=0.035(\mathrm{~m})$

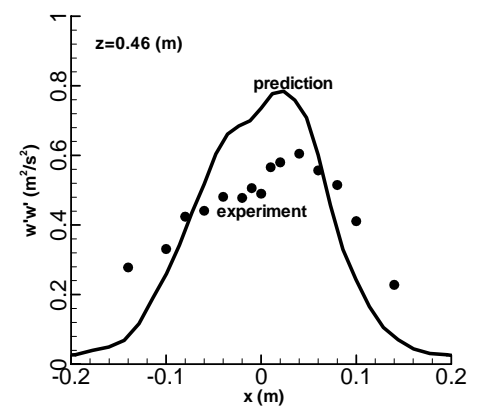

b) $\mathrm{z}=0.46(\mathrm{~m})$

Fig. 3. Comparison between the predicted and measured longitudinal velocity fluctuation.

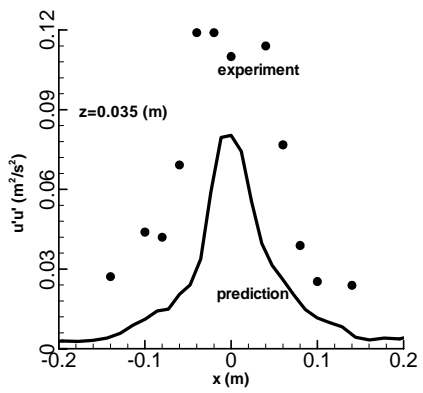

a) $\mathrm{z}=0.035(\mathrm{~m})$

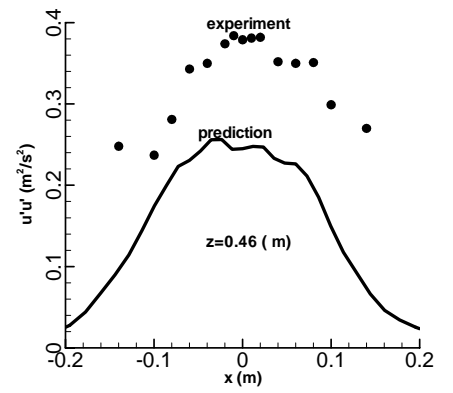

b) $\mathrm{z}=0.46(\mathrm{~m})$

Fig. 4. Comparison between the predicted and measured transversal velocity fluctuation.

For the second flame (cf. Fig. 1b), the presence of a pool fire at the base of the vertical burning wall, induces a significant thermal layer $(T>500 \mathrm{~K})$ at the floor level, evident in Fig. $5 a$ for the profiles of the mean temperature at $\mathrm{z}=0.13 \mathrm{~m}$. Near the vertical burning wall, the mean temperature is correctly predicted. While, far away from that region $(x>0.1 \mathrm{~m})$, the lateral extent of the diffusion flame is clearly under-predicted due to the one-step chemical reaction. As compared to pool-like fire, interaction between pool-like and vertical wall fires induces a larger transversal velocity $(\mathrm{u}=-0.7 \mathrm{~m} / \mathrm{s})$ at the flame base, and longitudinal velocity $(\mathrm{w}=3.4 \mathrm{~m} / \mathrm{s})$ near the exit $(\mathrm{z}=0.72 \mathrm{~m})$. In general terms, the experimental trend is reasonably reproduced by the numerical model. The predicted profiles of the longitudinal and transversal velocity fluctuations, w'w' and u'u', at $\mathrm{z}=0.015$ and $0.72 \mathrm{~m}$ are compared with the measured values in Fig. 6(a,b) and Fig. 7(a,b). The longitudinal velocity fluctuation, w' $w$ ', seems somewhat under-predicted at the base of the corner fire $(\mathrm{z}=0.015 \mathrm{~m})$, while over-predicted far away from the corner $(\mathrm{z}=0.72 \mathrm{~m})$. However, the transversal velocity fluctuation, u'u', is always under-predicted as compared to the experiment one. Globally, as compared to the prediction of the pool-like fire, the quality of the agreement between prediction and experiment for the vertical wall 
fire deteriorates. The high levels of the measured velocity fluctuation, u'u', due to the presence of large-scale coherent structures can not be correctly predicted. The divergence between prediction and experiment highlights the serious shortcoming in the standard Smagorinsky constant $\left(\mathrm{C}_{\mathrm{s}}=0.2\right)$ used in LES approach which fails to describe the turbulent mixing of the vertical wall fire.

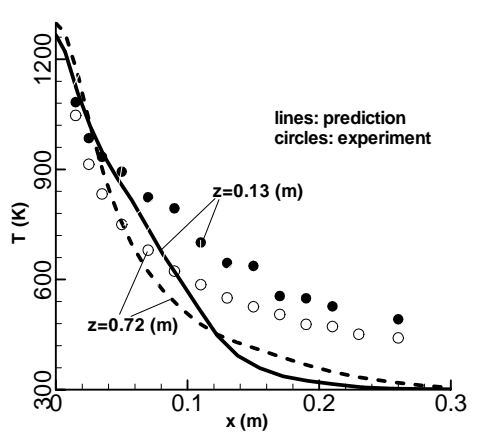

a) temperature

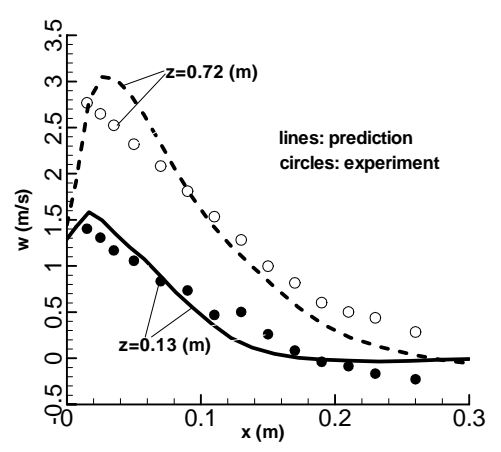

b) longitudinal velocity

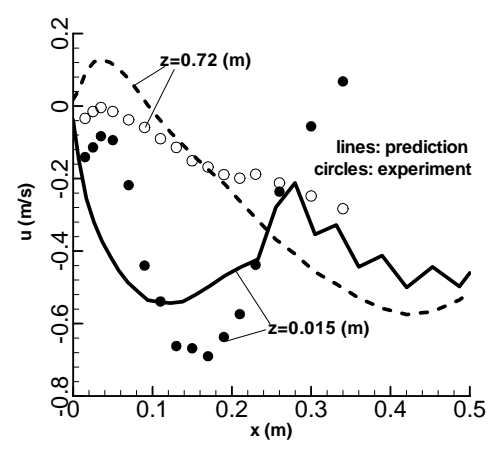

c) transversal velocity

Fig. 5. Comparison between the predicted and measured mean value.

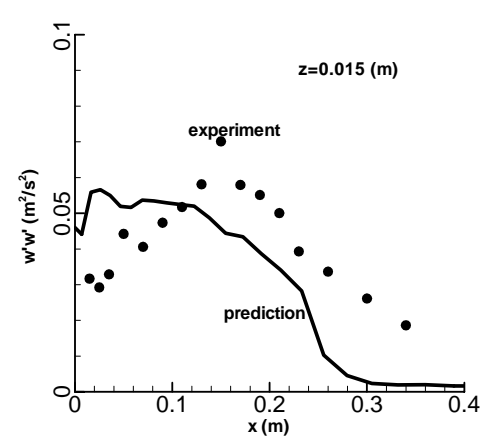

a) $\mathrm{z}=0.015(\mathrm{~m})$

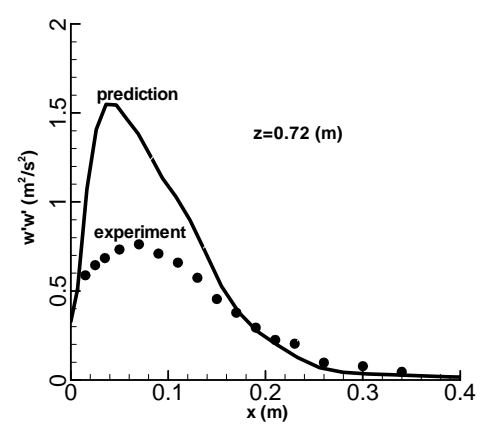

b) $\mathrm{z}=0.72(\mathrm{~m})$

Fig. 6. Comparison between the predicted and measured longitudinal velocity fluctuations. 


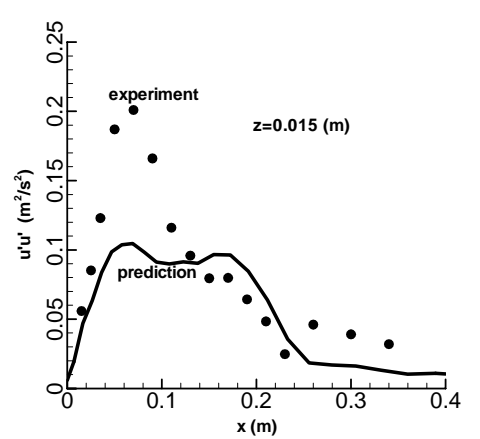

a) $\mathrm{z}=0.015(\mathrm{~m})$

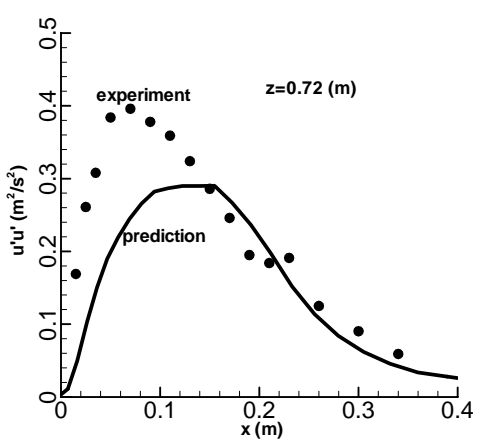

b) $\mathrm{z}=0.72(\mathrm{~m})$

Fig. 7. Comparison between the predicted and measured transversal velocity fluctuations.

The last flame characterized by a fire propagation behind a burner (pyrolysis zone) along a vertical wall (cf. Fig. 1c) is examined. Figure 8(a,b) shows the profiles for the predicted and measured mean temperature, $\mathrm{T}$, and the longitudinal velocity, w. Globally, agreement between prediction and measurement is relatively good in terms of magnitude and distribution. The temperature progressively decreases with the height, $\mathrm{z}$, from the burner (pyrolysis zone) as energy is convected away from the hot flame region. However, analysis of temperature profiles shows that the model overpredicts the temperature peak near the burner at $\mathrm{z} / \mathrm{H}_{\mathrm{b}}=1.5$, and underpredicts the extent of the higher temperature regions far away from the vertical wall $(x>0.07 \mathrm{~m})$. A consequence of the temperature profiles is the significant discrepancies for the extent of the higher velocity regions far away from the vertical wall $(x>0.07 \mathrm{~m})$ with an underprediction of about $30 \%$. The maximum fluid velocity, occurring in the high temperature region, first increases with elevation, z, due to the combined effects of natural convection and air entrainment, and later remains almost constant far away from the burner (pyrolysis zone) due to turbulence development. In this study, only for the case of wall fire propagation (Fig. 1c), the flamesurface heat flux downstream behind the burner (pyrolysis zone) for $\mathrm{z} \geq \mathrm{H}_{\mathrm{b}}(=0.5 \mathrm{~m})$ is examined, because this zone is responsible for the fire to spread over a condensed fuel surface. Some interesting information can be drawn by displaying the isolines of the convective, radiative and total heat flux in the y-z plane, as shown in Fig. 9(a,b,c,d). It is worth noting that conditions similar to those of an equilibrium turbulent boundary layer (Couette flow [12]) are assumed to prevail near the wall surface, and the convective heat feedback (Fig. 9a) is calculated from

$$
\dot{q}_{\text {conv }}=\frac{\left(T_{g}-T_{s}\right) \rho_{C_{p}} C_{\mu}^{1 / 4} k^{1 / 2}}{\operatorname{Pr}\left[\frac{1}{\kappa} \ln \left(E y^{+}\right)+P\right]}
$$

far away from the wall for viscous effects to be negligible, that is, at $\mathrm{y}^{+} \geq 30$. Here, $\mathrm{T}_{\mathrm{g}}$ denotes the gas temperature and $\mathrm{T}_{\mathrm{s}}$ wall surface temperature; the other symbols are defined in Ref. [12]. The convection flux (Fig. 9a) is found to progressively increase downstream behind the burner (pyrolysis zone) to a maximum at $\mathrm{z} / \mathrm{H}_{\mathrm{b}}=2$, mainly due to the enhancement of the turbulence level. Far away from that region for $\mathrm{z} / \mathrm{H}_{\mathrm{b}}>2$, decrease of the convection flux is principally due to a reduction in the temperature gradient near 
the wall surface. The flame radiation contribution to the wall surface, as presented in Fig. 9b, is computed from a discrete representation of the radiative intensity field (Eq. 10). The flame radiation flux is found to decrease monotoneously with height downstream behind the burner (pyrolysis zone) due to the attenuation of reacting zone. It appears that for the vertical wall fire, the radiation flux seems to play a secondary role, and the maximum contribution by convection accounts for about $75 \%$ of the total heat flux. During experiment, the total heat feedback to the wall was measured by means of the radiometers. Measurements of the total heat flux $\left(q_{\text {conv }}+q_{\text {rad }}\right)$ downstream behind the burner (pyrolysis zone) are also presented in Fig. 9d, and considered as a reference for validating the numerical models. It can be seen that agreement between predicted (Fig. 9c) and measured (Fig. 9d) mean total heat flux $\left(\mathrm{W} / \mathrm{cm}^{2}\right)$ is relatively good in terms of magnitude and distribution. However, the experimentally-determined total heat flux appears more perturbed as compared to the predicted one. Because the task of obtaining accurate measurement of the total heat flux is still very difficult in a buoyancy-dominated turbulent fire.

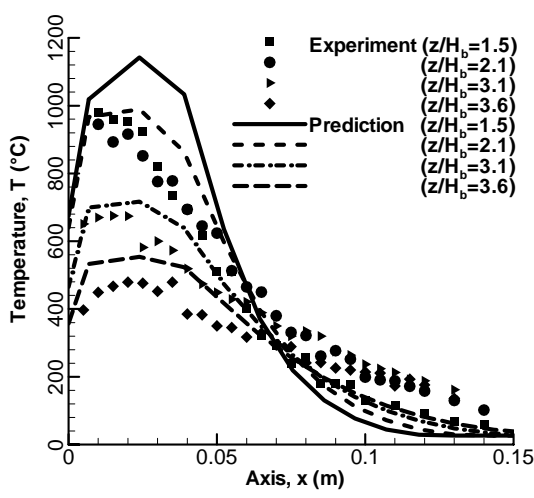

a) temperature

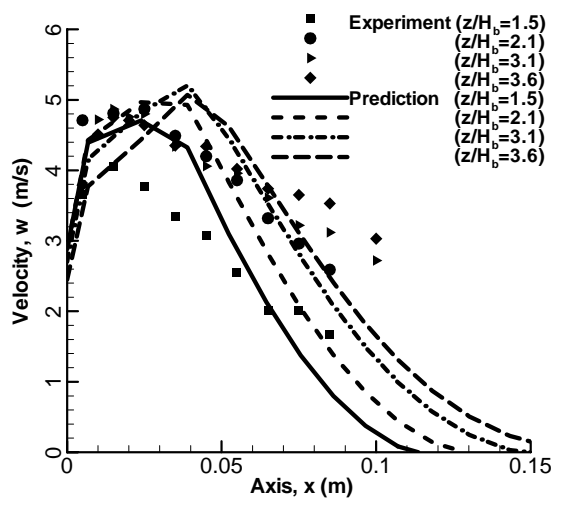

b) longitudinal velocity

Fig. 8. Comparison between the predicted and measured mean value.

During combustion, the formed soot is transported by the fire-induced flow through convection and diffusion, and plays an important role on flame radiation. Therefore, the predicted soot volume fraction contours for the three fire configurations are also examined in Fig. 10(a,b,c). A similar trend of the soot formation in the diffusion flame subjected to a buoyancy-induced flow is observed. In all the cases, soot production seems to occur close to the high temperature fuel-rich side of stoichiometric, and decays rapidly once in the fuel-lean region. For the case of wall fire propagation behind a vertical burner (pyrolysis zone), a peak soot volume fraction value of about $5.5 \times 10^{-7}$ is predicted, and however, for the pool-like and corner fires, this peak value is only about $3 \times 10^{-7}$. It seems that the higher temperature level $(\mathrm{T}>1400 \mathrm{~K})$ at lower base of the vertical wall fire $\left(\mathrm{z} / \mathrm{H}_{\mathrm{b}}<1.5 \mathrm{~m}\right)$ induces a slight increase of the soot formation. Globally, these peak values are consistent with that experimentally-determined for the propane-air diffusion flame. 


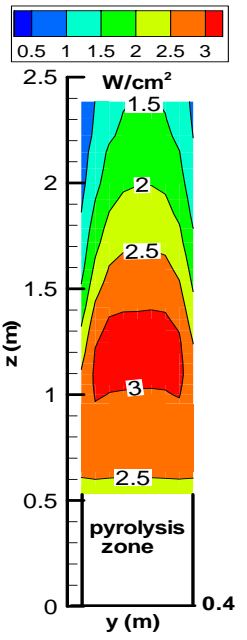

a)

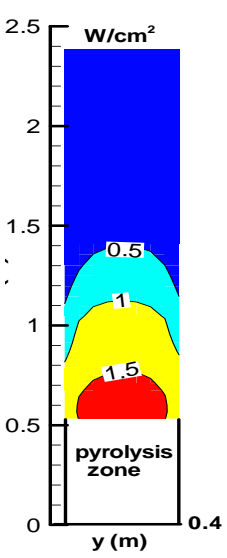

b)

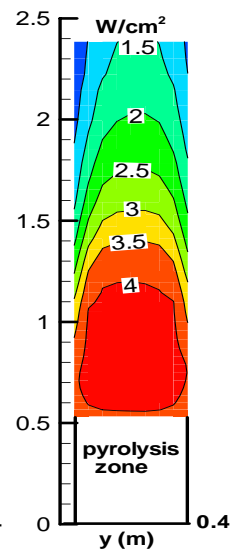

c)

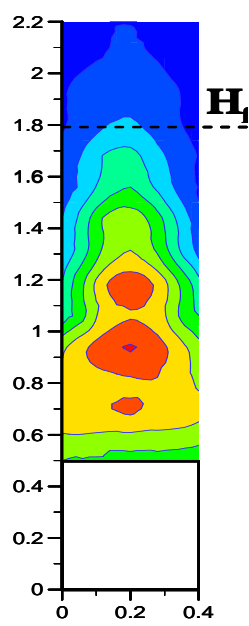

d)

Fig. 9. Contours of the heat flux from the flame to the wall. a) predicted convection flux; b) predicted radiation flux; c) predicted total heat flux; d) measured total heat flux.

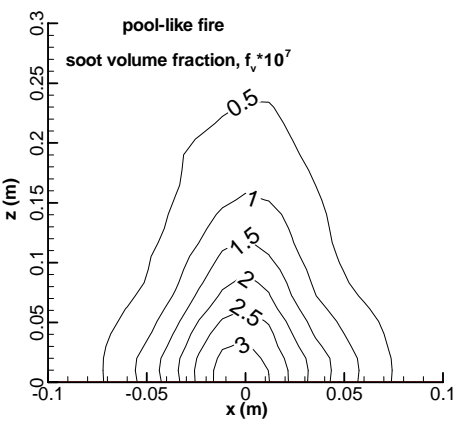

a) pool-like fire

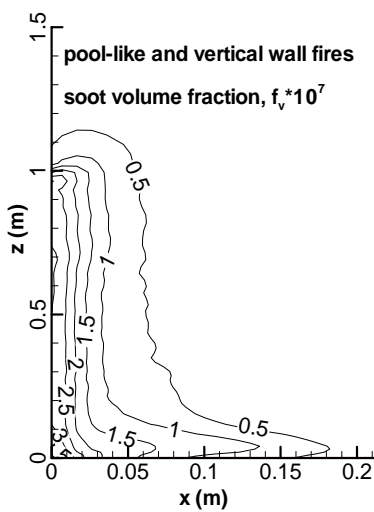

b) pool-like/ wall fires

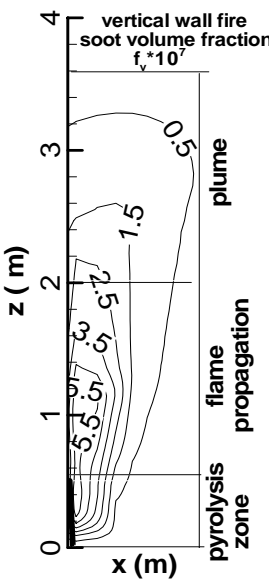

c) vertical wall fire

Fig. 10. Predicted contours of soot volume fraction $\left(\mathrm{f}_{\mathrm{v}} \times 10^{7}\right)$.

\section{CONCLUSION}

An Eddy Break-Up model coupled with a Large Eddy Simulation is tested by modeling three characteristic fires in an intermediate scale. The numerical results show that interaction between turbulence and soot oxidation is correctly predicted by using EBU concept. Globally, the predicted mean temperature and velocity profiles are in good agreement with the experimental data. The measured results suggest that a buoyancycontrolled fire produces a complex time-dependent temperature and velocity fields. The behavior of the large-scale, highly fluctuating temperature and velocity fields due to buoyancy is reasonably well reproduced by the numerical simulation. For the vertical wall fire, contribution by radiation is lower than $40 \%$ of the total heat flux, and 
convection can become a dominant mode of heat transfer along the vertical burning wall. In general, the velocity fluctuation is underpredicted as compared to measured one, particularly for the vertical wall fire, due to the standard Smagorinsky sub-grid scale model based on a constant $C_{s}=0.2$. Ongoing work is accounting for a dynamique subgridscale turbulence model for modeling the bouyancy-controlled, vertical wall fire.

\section{REFERENCES}

[1] Hostikka, S., McGrattan, K.B., and Hamins, A., "Numerical Modeling of Pool Fires Using LES and Finite Volume Method for Radiation," Proceeding of the Seventh International Symposium on Fire Safety Science, 2002, pp. 383-395.

[2] Becker, H.A., and Yamazaki, S., "Entrainment, Momentum Flux and Temperature in Vertical Free Turbulent Diffusion Flames," Combustion and Flame, 33, pp. 123-149, (1978).

[3] Bouhafid, A., Vantelon, J.P., Joulain, P., and Fernandez-Pello, A.C., "On the Flame Structure at the Base of a Pool Fire," Twenty-Second Symposium (International) on Combustion, Pittsburgh : The Combustion Institute, 1988, pp. 1291-1298.

[4] Tamanini, F., "Reaction Rate, Air Entrainment and Radiation in Turbulent Fire Plumes," Combustion and Flame, 30, pp. 85-101, (1977).

[5] Annarumma, M.O., Most, J.M., and Joulain, P., "On the Numerical Modeling of Buoyancy-Dominated Turbulent Vertical Diffusion Flames,” Combustion and Flame, 85, pp. 403-415, (1991).

[6] Wang, H.Y., Joulain, P., and Most, J.M., "On the Numerical Modeling of Buoyancy-Dominated Turbulent Diffusion Flames by Using Large Eddy Simulation and $\mathrm{k}-\varepsilon$ Turbulence Model," Combust. Sci. and Tech., 176, pp. 1007-1034, (2004).

[7] You, H.Z., and Faeth, G.M., "Turbulence Combustion: Buoyant Axisymmetric Turbulent Diffusion Flames in Still Air,” Combustion and Flame, 44, pp. 261, (1982).

[8] Magnussen, F., and Hjertager, B.H., "On Mathmatical Modelling of Turbulent Combustion with Special Emphasis on Soot Formation and Combustion," Sixteenth Symposium (International) on Combustion. Pittsburgh: The Combustion Institute, 1977, pp. 719-731.

[9] Smagorinsky, J., "General Circulation Experiments with the Primitive Equations I. the Basic Experiment," Monthly Weather review, 91, pp. 99, (1963).

[10] McGrattan, K.B, Glenn, P.F., and Jason, E.F., "Fire Dynamics Simulator Technical Reference Guide,” NIST Technical Report, 2004.

[11] Modak, A.T., "Radiation from Products of Combustion," Fire Research, 1, p. 339, (1979).

[12] Djilali, N., Gartshore, I., and Salcudean, M., "Calculation of Convective Heat Transfer in Recirculating Turbulent Flow Using Various Near-wall Turbulence Models," Numerical Heat Transfer, 16, pp. 189-212, (1989). 